\title{
EDITORIAL
}

\section{Hyperbaric Oxygen Therapy: Scopes and Limitations}

Hyperbaric Oxygen therapy (HBOT) has been used for a wide variety of medical conditions over past 40 years. It has a rich and diverse history around the world. In 1772 English scientist Joseph Priestley isolated elemental Oxygen. 100 years later, elemental Oxygen was combined with barometric chamber to provide HBOT to treat decompression illness of deep sea divers. In 1937, Behnke \& Shaw used HBOT to treat decompression sickness and published in Naval Medical Bulletin. 1950s and early 60s saw a rise in application of HBOT. Dr. Ite Boerema treated gangrene with HBOT and later reported first use of HBOT in performing cardiac surgery.

The word hyperbaric means greater than normal (sea level) pressure. According to the Undersea and Hyperbaric Medical Society (UHMS) HBOT is defined as the administration of $100 \%$ Oxygen in a contained chamber pressurized to a greater than or equal to 1.5 times atmospheric pressure. They developed a list of conditions where HBOT is indicated which is updated in every two years. This conditions have reasonable scientific evidence or well-validated clinical experiences. The use in acute air embolism and decompression illness takes advantage of physical compression of gas bubble which occur as atmospheric pressure rises. Other conditions include carbon monoxide poisoning, crush injury, problem wound, chronic refractory osteomyelitis, necrotizing soft tissue infection, clostridial myonecrosis, exceptional blood-loss anemia, radiation ulcer, thermal burn, compromised grafts and flaps and intracranial abscess.

HBOT is based on certain gas laws like Boyle's, Charles, Dalton's \& Henry's which say at depth increased density of gas molecules will increase the amount of those gases entering the blood. At sea level plasma $\mathrm{O}_{2}$ concentration is $3 \mathrm{ml} / \mathrm{L}$. Tissue at rest requires $60 \mathrm{ml}$ of $\mathrm{O}_{2}$ per liter of blood to maintain cellular metabolism. When atmospheric pressure is 3 ATA dissolved $\mathrm{O}_{2}$ approaches $60 \mathrm{ml} / \mathrm{L}$ of plasma which is sufficient to supply resting total $\mathrm{O}_{2}$ requirement without contribution from hemoglobin. $\mathrm{O}_{2}$ at 3 ATA increases $\mathrm{O}_{2}$ tension in arterial blood to nearly 270 $\mathrm{kPa}$ and in tissue to about $53 \mathrm{kPa}$.This improves the cellular $\mathrm{O}_{2}$ supply by raising the tissue-cellular diffusion gradient. This hyperoxia promotes angiogenesis and wound healing, kills certain anaerobes, prevent growth of pseudomonas, prevent production of clostridial toxin, restore neutrophil mediated bacterial killing and reduces leucocyte adhesion in reperfusion injury.

HBOT is a simple non-invasive and painless treatment. The session includes three phases which are compression, treatment and decompression.

HBOT is administered by placing the patient in a chamber where upon $100 \%$ Oxygen is respired at atmospheric pressure ranging from 2 times sea-level to 2.4 times that experienced at sea level. The duration of treatment varies from 45 to 300 minutes and patient may require up to 40 sessions. Strict monitoring is required and the facility for immediate resuscitation including mechanical ventilation should be available. There are three types of hyperbaric chamber: Monoplace, Multiplace and Portable.

HBOT has predictable occurrence of side effects, commonly otic barotrauma, rarely grand mal seizure. Reversible myopia, hypoglycemia are other mild side effects. If pressure do not exceed $300 \mathrm{kPa}$ and time is less than 120 minutes, HBOT is safe. COPD is a relative contraindication which may predispose to pneumothorax, arterial gas embolism, even death. There are other contraindications to HBOT like sinus infection, congestive cardiac failure, uncontrolled seizure, low blood sugar pregnancy etc.

There are ongoing clinical trials around the world that may prove benefits of HBOT for various medical conditions. Clinical trials for use in various neurological disorders like stroke, autism, autism 
spectrum disorder reveal variable results. It has been shown ineffective in diseases like multiple sclerosis and dementia but it continues to be used.

From 2015, Department of Plastic Surgery of Dhaka Medical College and Hospital started treating patients with HBOT by 2 monoplace chambers. About 100 patients have been treated so far for various reasons like superficial burns, inhalation burn, diabetic foot ulcer, radio necrotic ulcer, non-healing wound, compromised skin grafts and flaps and neuropathic ulcer. Results are promising.

A research work was carried out in the Department of Plastic Surgery, DMCH on "Role of HBOT in non healing wound- first Bangladesh study". The researchers found that the wound perfusion and oxygenation was increased after administration of HBOTas well as the wound size was reduced significantly. This study showed that HBOT is an effective modality for non healing wounds. But, further research in this area is required to determine optimal HBOT dose, duration and patient selection criteria to make any final comment.
The field of HBOT will continue to grow and widened field of use may prove beneficial to more and more patients.

(J Bangladesh Coll Phys Surg 2019; 37: 105-106)

DOI: https://doi.org/10.3329/jbcps.v37i3.41730

Prof. Rayhana Awwal

Professor and Head

Department of Plastic Surgery and Burn Unit

Dhaka Medical College \& Hospital.

\section{References:}

1. Ahmed T, Kalam MA, Khondoker MS, Awwal R, Imam H. Hyperbaric Oxygen Therapy: Role in Medical Practice. Bangladesh Journal of Plastic Surgery 2014; 5(2): 50-61.

2. Dauwe PB, Pulikkottil BJ, Lavery L, Stuzin JM, Rohrich RJ. Does Hyperbaric Oxygen Therapy work in facilitating acute wound healing: A systemic review. Plastic and Reconstructive Surgery Journal 2013; 33(2): 208-2015.

3. Fife CE, Eckert KA, Carter MJ. An Update on the Appropriate Role for Hyperbaric Oxygen: Indications and Evidence. Plastic and Reconstructive Surgery Journal 2013; 138(3): 107-116.

4. Carney AY. Hyperbaric Oxygen therapy An Introduction. Crit Care Nurs Q. 2013; 36(3): 274-279.

5. Leach RM, Rees PJ, Wilmshurst P. ABC of oxygen Hyperbaric Oxygen Therapy. British Medical Journal. 1998; 317(24): 1140-1143. 